\title{
Unusual presentation of interrupted aortic arch: a case report and radiological review
}

\author{
Yadav A. ${ }^{1}$, Garg S. ${ }^{2}$, Bhagat M. ${ }^{3}$, Gurudatta . $^{4}$ \\ ${ }^{1}$ Dr. Alisha Yadav, Post Graduate Student, ${ }^{2}$ Dr. Shivane Garg, Post Graduate Student, ${ }^{3}$ Dr. Bhagat M., Assistant \\ Professor, Radiology, ${ }^{4}$ Dr. Ekjot Gurudatta, Post Graduate Student, all authors are affiliated with Department of \\ Radiodiagnosis, Sri Aurobindo Medical College and Post Graduate Institute, Indore, MP, India.
}

Address for Correspondence: Dr. Alisha Yadav, Department of Radiology, Sri Aurobindo Medical College and Post Graduate Institute, Indore, Madhya Pradesh, India. Email: yalisha007@gmail.com

\begin{abstract}
Interrupted aortic arch, arare congenital malformation and there is a loss of luminal continuity between the ascending and descending portions of the aortic arch. Their incidences are of 3 per million live births and manage by surgical treatment. Till now only 12 cases of isolated interrupted aortic arch reported in adults. We notify the computed tomography imaging findings of a 29 -year-old femalepatients presented to our hospital. MDCT has advantages of a less scanning time with more spatial resolution and high temporal resolution. Fine anatomic structures can be evaluated by retrospective reconstruction.Within few years MDCT has become a primary diagnostic tool for evaluation of aortic abnormality.Volumetric scanning of chest done in 64 slices MDCT with plain and contrast enhanced (I.Vnon-ionic) contiguous axial images taken from chest and evaluated in appropriate window settings. Result: Multi-detector computed tomography (MDCT) angiography with a 64 slice MDCT were performed. The aortic arch is seen interrupted, approx. $1.8 \mathrm{~cm}$ long segment of aortic arch just after the origin of subclavian artery is not seen (absent), thick chunk of irregular calcification is seen in the region of termination of aortic arch. Descending thoracic aorta is smaller in caliber measure approx. $1.1 \times 1.2$ $\mathrm{cm}$ in diameter \& shows well luminal contrast opacification. Prominent Para vertebral collaterals seen suggesting collateral filling of descending thoracic aorta. No evident contrast filled patent ductus arteriosus seen, a tubular slightly enhancing structure seen in this region.
\end{abstract}

\section{Introduction}

Interrupted aortic arch (IAA) is a rare congenital malformation, with incidence of 3 per million live births [1]. Steadily in 18 century described Interrupted aortic arch as a complete luminal and anatomic discontinuity between the ascending and descending aorta [2]. In majority of cases, IAA occur with an intracardiac malformation such as ventricular septal defect, left ventricular outflow tract obstruction, bicuspid aortic valve, patent ductus arteriosus, or aortopulmonary window. MDCT has advantages of a less scanning time with more spatial resolution and high temporal resolution. Fine anatomic structures can be evaluated by retrospective reconstruction [3]. The first classification system of interrupted aortic arch was introduced by Celoria and Patton [4].

This system describes and classifies the site of discontinuity in aortic arch, which can be distal to the left subclavian artery (type-A), which is $43 \%$; between the left carotid and left subclavian arteries (type-B), commonest type (53\%); or between the innominate and left carotid arteries (type-C) which constitute $4 \%$.

\section{Case Report}

In September 2014, a 29-year-old woman presented at our hospital because of respiratory symptoms. She had complained of breathlessness, which was progressive and increased in past few days. She related a history of

Manuscript received: $18^{\text {th }}$ November 2017

Reviewed: $28^{\text {th }}$ November 2017

Author Corrected: $6^{\text {th }}$ December 2017

Accepted for Publication: $12^{\text {th }}$ December 2017 


\section{Case Report}

increased blood pressure in her right arm; this problem had been observed after the birth of her 2nd child and again after the birth of her 3rd child. On physical examination, peripheral pulses were palpable over the carotid arteries and in the upper limbs, with a radial pulse that was stronger in the right arm than in the left. Bounding pulses in the neck were also detected. The blood pressure was $144 / 70 \mathrm{mmHg}$ in the right arm and 82/59 $\mathrm{mmHg}$ in the left arm. Lower-limb pulses were not palpable. Echocardiography was not performed, and chest radiography revealed cardiomegaly, bilateral pleural effusion and feature of pulmonary edema.

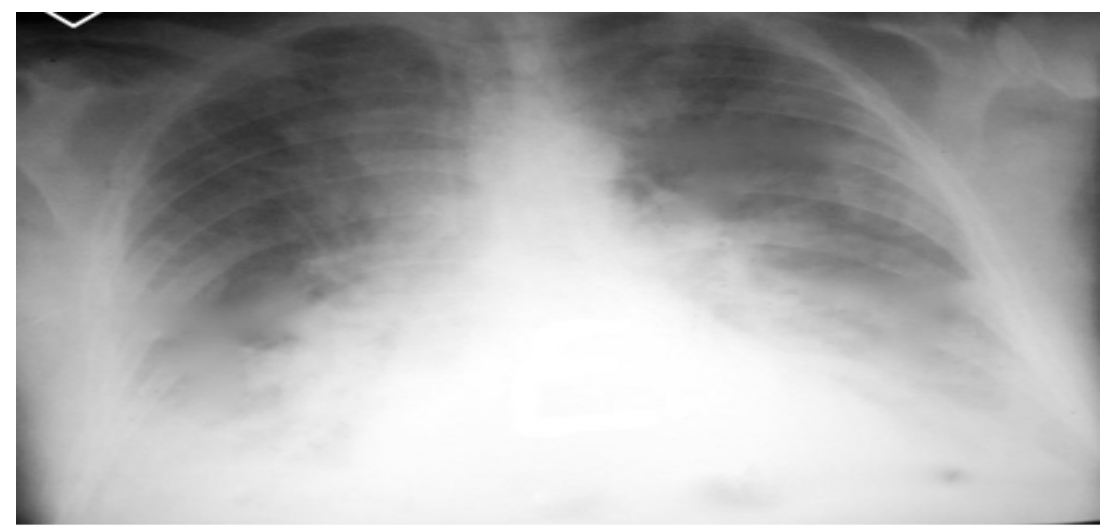

Fig 1:A 29-year-old woman radiography revealed cardiomegaly, bilateral pleural effusion and feature of pulmonary edema.

Volumetric scanning of chest done in 64 slices MDCT with plain and contrast enhanced ( I.V nonionic) contiguous axial images taken from chest and evaluated in appropriate window settings. The aortic arch was interrupted, approx. $1.8 \mathrm{~cm}$ long segment of aortic arch just after the origin of subclavian artery was not seen (type A interruption), thick chunk of irregular calcification was seen in the region of termination of aortic arch.Descending thoracic aorta was smaller in caliber measure approx. $1.1 \times 1.2 \mathrm{~cm}$ in diameter \&shows well luminal contrast opacification.Prominent Para vertebral collaterals seen suggesting collateral filling of descending thoracic aorta. No evident contrast filled patent ductus arteriosus seen, a tubular slightly enhancing structure seen in this region.

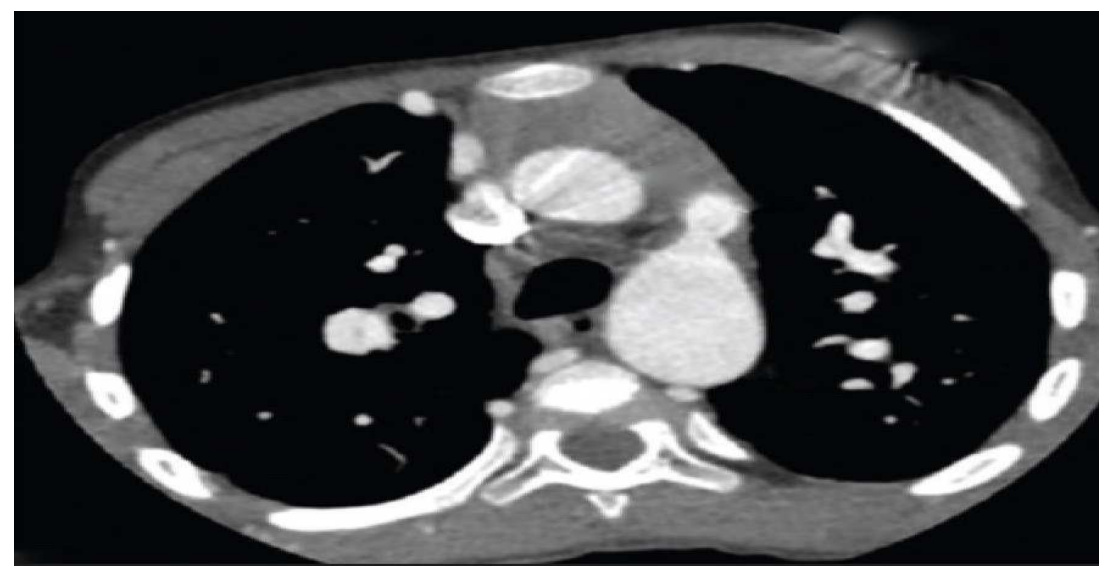

Fig 2: CT suggestive of interrupted aortic arch (type A interruption), thick chunk of irregular calcification was seen in the region of termination of aortic arch.

Proximal aortic arch, it's branches \& ascending aorta is normal in caliber, measure $2.6 \times 2.5 \mathrm{~cm}$. There were slight circumferential wall thickening of ascending aortaarch, brachiocephalic artery and both common carotid artery with focal calcification at places. Common carotid artery\&subclavian artery were normal in caliber with adequately contrast opacified lumen. Multiple collaterals seen particularly in lateral \& posterior chest wall, pre para vertebral region with prominent internal mammary artery. Visualized upper abdominal aorta is smaller in caliber\& seen well contrast opacified, Cardiomegaly noted, left ventricle wall appear thick, prominent left atrium and pulmonary veins noted in the lung. There was extensive coronary artery calcification without 


\section{Case Report}

significant lymphadenopathy. There was mild bilateral pleural effusion and consolidation of underlying posterior aspect of basal lung. There was smooth thickening of interlobular septa in both lung, patchy area of consolidation in Right upper \& middle lobe of lung \& small sub pleural consolidation in right lower lobe basal segment.

Thickening of fissure noted.

- A small wedge-shapedhypo density seen in spleen - infarct.

- No lytic lesion in visualized bone.

\section{Discussion}

Interrupted aortic arch is a rare congenital malformation accounting for only $1 \%$ of congenital heart diseases, defined as a complete absence of flow between 2 parts of the aorta. Altered hemodynamics through the fourth aortic arch and teratogenic exposure during the intrauterine period are thought to be itspotential causes.

During organogenesis many pairs of aortic arches join to form ventral and dorsal aortas. Abnormal regression of aortic arch, next to left subclavian artery form type A interruption. Type B occurs when the left fourth aortic arch regresses before the subclavian artery.

In infants, its clinically present as severe congestive heart failure; if left untreated, $90 \%$ of them die at a median age of 4 days [5]. In few in adults, itspresentation ranges from a lack of symptoms to limb swelling with differential blood pressures in all extremities. Substantial collateral circulation is present to maintain flow and enable survival. However, collateral vessels are subject to atrophy and atherosclerosis, which lead to other problems [6].

The advantages of multidetector CT are short scan time with reduced requirement for sedation, higher spatial resolution, and simultaneous evaluation of the airway and the lung with the caveat of exposure to ionizing radiation [7].

Detailed anatomy of vascular structures, their spatial relationship to adjacent organs combined with availability of post processing options such as maximum-intensity projection, multiplane reconstruction and volume rendering; it has significant advantage in comparison to other imaging modalities in evaluation of aortic arch anomalies. Three-dimensional reconstruction images are threedimensional and clearly delineate the spatial position of large vessels. MDCT has become a principle diagnostic method for evaluation of thoracic aortic abnormality. By this noninvasive technique detailed status of tracheal, esophageal compression and vascular anomalies can be seen. Disadvantages of this technique are the use of iodinated contrast material and increase in patient radiation exposure.

\section{Funding: Nil, Conflict of interest: None Permission of IRB: Yes}

\section{References}

1. Steidele RJ. Sammlung verchiedener in der chirurg. Prakt Lehschule Gemachten Beobb (Viena) 1778;2:114.

2. Goo HW, Park IS, Ko JK, Kim YH, Seo DM, Yun TJ, Park JJ, Yoon CH. CT of congenital heart disease: normal anatomy and typical pathologic conditions. Radiographics. 2003 Oct;23 Spec No: S147-65.

3. Pannu HK, Flohr TG, Corl FM, Fishman EK. Current concepts in multi-detector row CT evaluation of the coronary arteries: principles, techniques, and anatomy. Radiographics. 2003 Oct; 23 Spec No:S111-25.

4. CELORIA GC, PATTON RB. Congenital absence of the aortic arch. Am Heart J. 1959 Sep;58:407-13.

5. Collins-Nakai RL, Dick M, Parisi-Buckley L, Fyler DC, Castaneda AR. Interrupted aortic arch in infancy. J Pediatr. 1976 Jun; 88(6):959-62.

6. Krieger KH, Spencer FC. Is paraplegiaafterrepair of coarctation of the aorta due principally to distalhypotension during aorticcross-clamping? Surgery. 1985 Jan;97(1):2-7. 


\section{Case Report}

7. Yang DH, Goo HW, Seo DM, Yun TJ, Park JJ, Park IS, Ko JK, Kim YH. Multislice CT angiography of interrupted aortic arch. Pediatr Radiol. 2008 Jan;38(1):89-100. Epub 2007 Oct 27.

8. Dillman JR, Yarram SG, D'Amico AR, Hernandez RJ. Interrupted aortic arch: spectrum of MRI findings. AJR Am J Roentgenol. 2008 Jun; 190 (6):1467-74. doi: 10.2214/AJR.07.3408.
9. Reardon MJ, Hallman GL, Cooley DA. Interrupted aortic arch: Brief review and summary of an eighteen-year experience. Tex Heart Inst J 1984; 11:250-9.

10. Ho SY, Wilcox BR, Anderson RH, Lincoln JC. Interrupted aortic arch--anatomical features of surgical significance. Thorac Cardiovasc Surg. 1983 Aug;31(4):199-205.

\section{How to cite this article?}

Yadav A, Garg S, Bhagat M, Gurudatta E. Unusual presentation of interrupted aortic arch: a case report and radiological review. Int J Med Res Rev 2017;5 (12):1022-1025.doi:10.17511/ijmrr. 2017.i12.08 